\title{
EXPLORING THE MOTIVES TO VISIT BELGRADE BY APPLYING AHP METHOD
}

Sanja Božić,

Tamara Višnić,

Milan Ivkov, Miroslav D. Vujičić

University of Novi Sad, Faculty of Sciences, Department of Geography, Tourism and Hotel Management, Novi Sad, Serbia
Correspondence:

Sanja Božić

e-mail:

sanja.bozic@dgt.uns.ac.rs
Abstract:

The principal aim of this paper is to explore the motives to visit Belgrade (the capital city of Serbia), by applying the AHP (Analytical Hierarchy process) method, as a new approach to exploring motivation in the tourism field. The survey was conducted in the form of an interview among 30 tourists in Belgrade, and the respondents were asked to express their preferences using Saaty's scale between different motives of visit. The motives included in the study were: Cultural motive, Business motive, Nightlife and entertainment, Religious motive and Gastronomy. For each motive, the study also explored sub-motives and, as a result, the ranking is provided for each group of motives and their sub-motives. The results indicate that the most dominant motives are Cultural motives (0.262) and Entertainment and night life (0.249), while the least dominant is Religious motive (0.058).

Keywords:

travel motivation, AHP, Belgrade, city tourism.

\section{INTRODUCTION}

Human behaviour is both directed towards satisfying certain needs, but it also results from them (Maslow, 1943). In order to understand motivation in tourism, it is necessary to understand what motivates tourists to choose a certain destination. Pearce, Morrison and Rutledge (1998) explain tourist motivation as biological and cultural forces that affect our travel choices, behavior and experience. People travel for various reasons in order to satisfy their different needs, which then influences their choices of destination. Hence, reasons to travel are the factors that affects people's choices of destinations in different ways. Therefore, it has been a significant subject of many tourism studies in the past, but also nowadays (Plog, 1974; Crompton, 1979; Dann, 1981; Pearce, 1995; Sirakaya \& Woodside, 2005; Hsu \& Huang, 2008; Li \& Cai, 2012; Jiang, 2015; Leong et al., 2015; Li et al., 2015).

Motivation research is of particular importance in tourism since travel is performed for a number of motives/reasons. Being conversant with the motives is the basis for understanding the key trends within the tourism market and the creation of an adequate program of marketing activities (marketing mix).

The paper sought to investigate the travel motives for visiting Belgrade. Belgrade is the capital of Serbia and has a population of around 1.6 million people. It is situated at the confluence of the Sava and the Danube 
rivers. It is the capital of Serbian culture, education, science and economy. As a result of its vivid and dynamic history, Belgrade has been home to many nationalities and is consider a multicultural city (Vujović, 2003), and it has become a very attractive tourism destination. The principal aim of this paper is to explore the motives to visit Belgrade, by applying the AHP (Analytical Hierarchy process) method. Although dating from 1980, the AHP method has recently found its application in tourism field (Lee \& Lee, 2015; Wang et al., 2016; Božić et al., 2016). The AHP approach is used to construct an evaluation model and calculate criterion weights. It is mainly used for ranking decision alternatives. This research provides the ranking of the pull motives to visit Belgrade, which could be useful to decision-makers on destination level, such as action plan makers, tourism organizations etc.

\section{METHOD}

For the purpose of this study, the AHP approach was implemented. This method, developed by Saaty (1980), is reputed to be one of the most commercially available decision making systems, as well as one of the most extensively used multi-criteria decision making methods. This method represents a "qualitative" technique that relies on the judgment and experience of decision makers. AHP gradually compares alternatives and measures their impact on the goal, which enables making the right decision (Saaty, 1980; Saaty, 2008). In tourism field, it is often used to make priorities in tourism strategies (Lee \& Lee, 2015), for the ranking of tourism preferences (Wang et al., 2016) or for making the hierarchy of travel motives to visit a certain destination (Božić et al., 2016) etc.

In this study, the goal is to obtain the ranking of the motives to visit Belgrade. The motives are criteria, while sub-groups within those two major groups are sub-criteria. As a result, we derived the criterion weights based on a survey done in Belgrade. This means that we didn't include several alternatives in the comparison, but we put an emphasis on the comparison of criteria, in this case motives for visit. The motives to visit Belgrade included in the study were chosen by suggestions of the panel of tourism experts (Professors in tourism field).

The survey was conducted in the form of an interview among 30 tourists in Belgrade. The interview was conducted from April to August, 2015 in the following hotels in Belgrade: Hotel Royal, Crowne Plaza, Holiday Inn, Slavija, Majdan and Srbija. The interviews were conducted with the help of hotel receptionists. Firstly, the respondents were asked to express their preferences (using Saaty's scale) between different motives of visit. After that, they were also asked to express their preferences separately between different subcategories of each group of motives. Thus, the final results of the study were based on the responds of 30 visitors of different age (average age 27.32 years), $59 \%$ of which were female, and the majority of them (63\%) on the territory of Serbia, while the rest were foreign visitors (Slovenia, Bosnia and Herzegovina, Austria, Germany, Hungary).

\section{RESULTS AND DISCUSSION}

The obtained data were analyzed in the Expert Choice 2000. As a result, the ranking of the motives to visit Belgrade was derived (Figure 1). It shows that the most dominant motive of visit is the cultural motive, followed by entertainment and nightlife and business motive, while the least dominant motives of visit are gastronomy and religious motive.

Dominance of the cultural motive $(26.2 \%)$ can be explained by the fact that Belgrade is one of the oldest cities in Europe with the rich cultural and historical heritage. This also resulted in the fact that Belgrade is nominated for the European city of culture for the year 2020. If we further analyze sub-motives within the cultural motive (Figure 2), it can be seen that the architecture of the city $(26.7 \%)$ and attractive cultural heritage (18.4\%) are the most dominant. At the moment, Belgrade has 333 cultural assets, 10 cultural-historical units, 296 monuments of culture, 21 archeological localities proclaimed by the Institute for Protection of Cultural Monuments (Development strategy of the city of Belgrade, 2008). This resulted in diverse architecture and rich cultural heritage from various periods, thus creating the basis for cultural tourism development.

The least dominant motive is permanent museum exhibitions. Belgrade has a wide array of museums from different areas (Natural, Ethnographic, City museum, Museum of Nikola Tesla etc.). However, it seems that their permanent exhibitions are not so attractive to tourists in comparison to other attractions. This finding requires some further research.

The cultural motive is followed by entertainment and nightlife (24.6\%), which assumed the second place. Belgrade is reputed to be a very vivid and exciting city, and many people, especially from the region, visit this city just to experience its rich nightlife.

The results show that the most dominant motives within entertainment and nightlife are of the respondents Diversity of entertaining programs (24.9\%) and 
Synthesis with respect to goal: The most dominant motive for visit of Belgrade Inconsistency $=0.02$

Cultural motive (0.262)

Entertinment and Nightlife (0.249)

Business (0.242)

Gastronomy (0.190)

Religious motive (0.058)

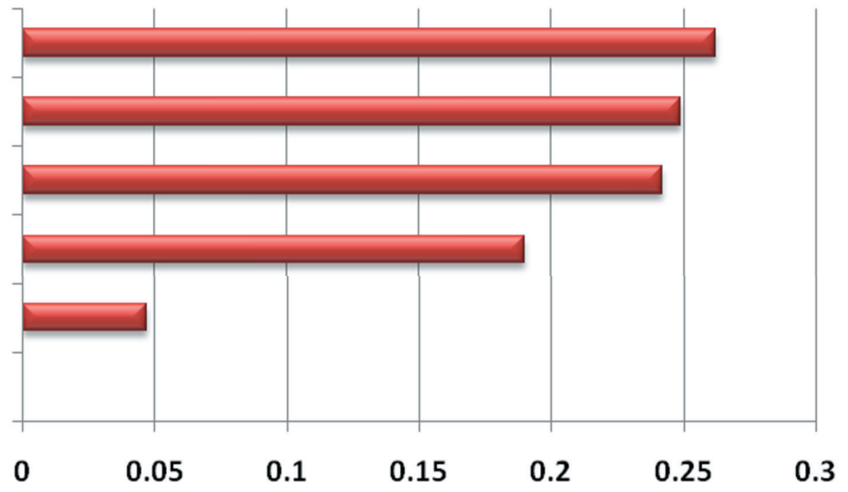

Figure 1. Ranking of the motives to visit Belgrade

Synthesis with respect goal: Ranking of the submotives of Cultural motive

Inconsistency $=0.03$

Arhitecture of the city $(0.267)$

Diversity of theatre performances $(0.184)$

Attractive cultural heritage $(0.164)$

Valuable art exibitions(0.145)

Good value for money(0.135)

Permenent museum exibitions (0.104)

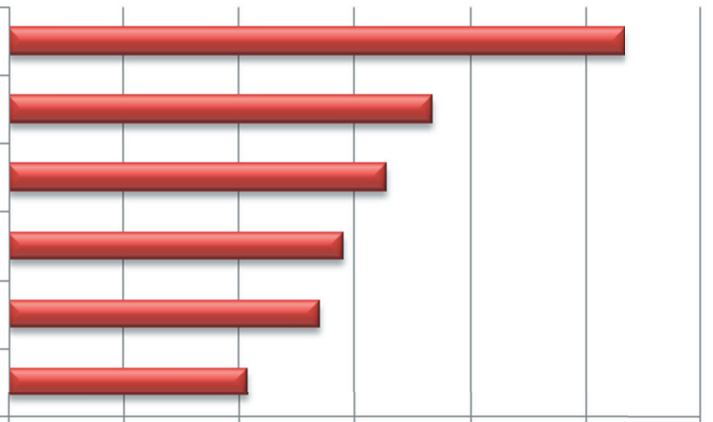

$\begin{array}{lllllll}0 & 0.05 & 0.1 & 0.15 & 0.2 & 0.25 & 0.3\end{array}$

Figure 2. Ranking of submotives within Cultural motive

Synthesis with respect to goal: Ranking of the submotives of

Entertainment and nightlife

Inconsistency $=0.01$

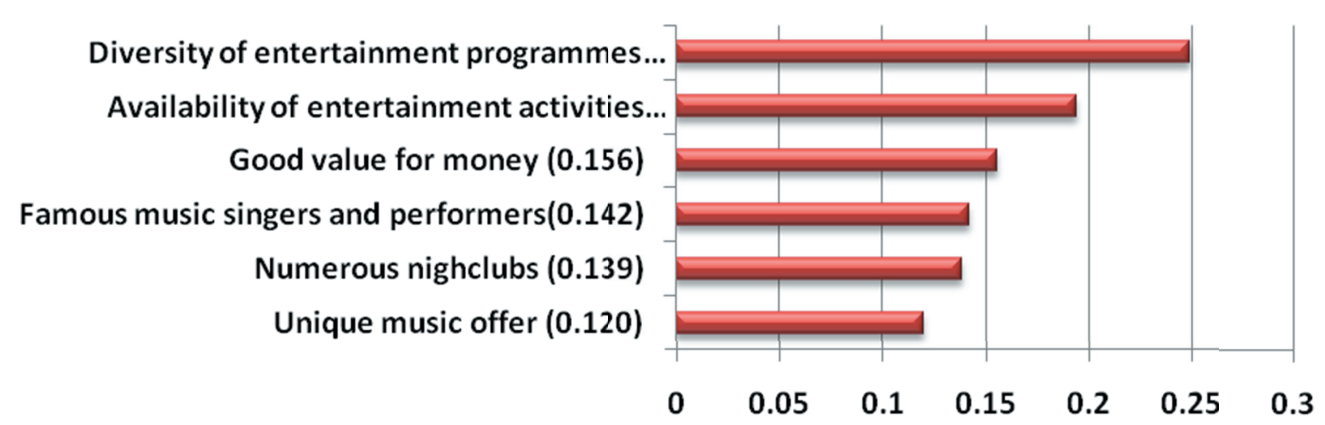

Figure 3. Ranking of sub-motives within Entertainment and Nightlife 




Figure 4. Ranking of sub-motives within business motive

Synthesis with respect to goal: Ranking of the submotives of

Gastronomy

Inconsistency $=0.02$

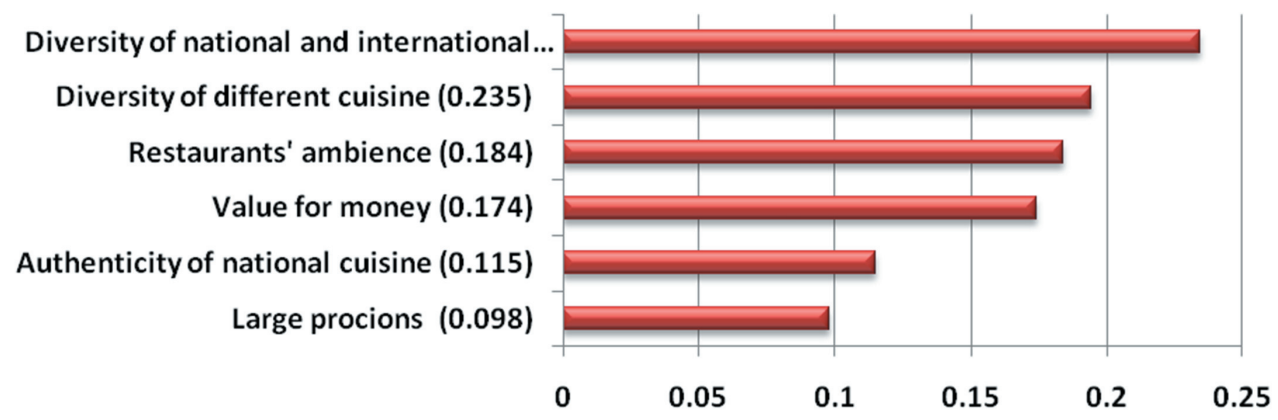

Figure 5. Ranking of submotives within Gastronomy motive

Synthesis with respect to goal: Ranking of the submotives within

Religious motive

Inconsistency $=0.05$

Artistic and architectural value of sacred sites(0.314)

Interesting religious ceremonies $\mathbf{( 0 . 1 8 2 )}$

Visit of religious site for pray $(0.173)$

Diversity of sacred sites $\mathbf{( 0 . 1 3 1 )}$

Learning about religion $(0.103)$

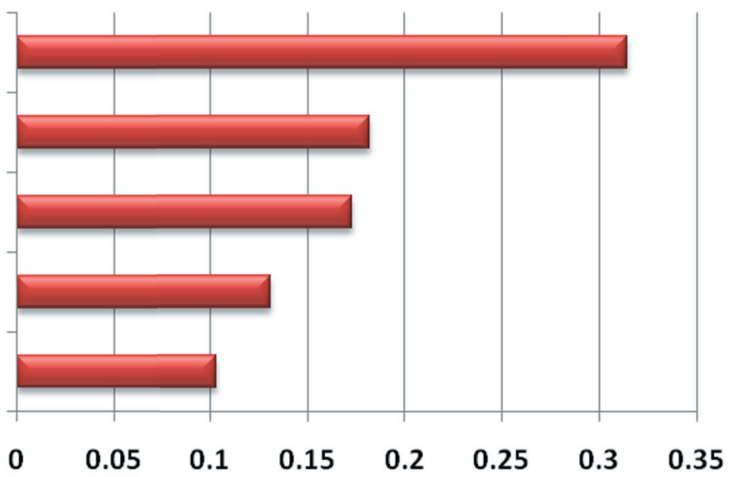

Figure 6. Ranking of submotives within Religious motive 
Availability of entertainment activities (19.4\%). On the other hand, the least ranked sub-motive is Unique music offer, as majority of tourists are from the Balkans, where music offer is quite similar to Serbian.

The third ranked motive is Business motive (24.2\%). This motive refers to the opportunities for organization of conferences, congresses and other business events, but also attractiveness of Belgrade as a business tourism destination. Since the establishment of the Serbia Convention Bureau (SCB) in May 2007, set up with continuing training and support from Gaining Edge ${ }^{1}$, Serbia has been attracting and winning many major events in the South East Europe despite being a relatively new player in the world conference market. According to ICCA report 2014, Belgrade obtained $50^{\text {th }}$ world ranking (for number of meetings per city - 50) and $27^{\text {th }}$ ranking in Europe, which indicates that Belgrade will soon be at the forefront of Europe's meetings industry (Gaining Edge, 2016).

The most dominant motives are Additional facilities and offer as well as Authenticity of place for making business. Belgrade is an attractive place for organization of various events and it offers wide range of different facilities for events from luxury hotels, equipped for organization of business meetings to congress centers (such as Sava centre).

Business motives are followed by Gastronomy motive (0.190). Gastronomy represents an important motive for visiting a certain destination, having in mind that it reflects the lifestyle of its habitants.

Heterogeneous cuisine, sharing the characteristics of the Balkans, the Mediterranean, Turkish and Hungarian cuisines is what distinguishes Belgrade from other destinations. There are currently 1401 restaurants in Belgrade $^{2}$ that offer traditional Serbian and international cuisine, so the results show the domination of Diversity of national and international restaurants (0.235) within the group gastronomy. Right after the diversity of national and international restaurants is a motive diversity of different cuisine (0.235), having in mind that tourists have the possibility to choose between different cuisines. On the other hand, the motive large portions (0.098) was considered the least important when visiting a restaurant.

The least ranked among others is religious motive (0.058), considering that all other motives are more attractive then religious ones.

Among the motives within religious motive, the first place was obtained by Artistic and architectural value of

1 Case study: Serbia Convention Bureau http://gainingedge. com/case-study-05/

2 Belgrade restaurants - www.restorani.biz/beograd/ sacred sites (0.314), having in mind that Belgrade boasts numerous objects of sacral architecture considered one of the most valuable in the Balkans. The last place in the religious motive category takes Learning about religion (0.103), which is considered the least important when visiting Belgrade.

\section{CONCLUSION}

Numerous empirical studies have explored travel motives for various destinations, by applying different methods. This article particularly shows the suitability of the AHP model for travel motivation research, by providing decision makers with a hierarchy of motives they should take into consideration according to their own priorities.

This study contributes to the overall understanding of what motivates tourists to travel to a specific destination. The findings revealed the most dominate travel motives influencing tourists to select Belgrade as their destination choice included Cultural motives (0.262), Entertainment and night life (0.249) and Business motives (0.242). When it comes to focusing the marketing efforts, marketing campaigns and promotional material should especially focus on cultural motives and night life and entertainment, since these were ranked as the highest motivators for tourists.

It is important to mention that this study also has certain limitations. The study sample predominantly consists of domestic tourists which could affect the hierarchy of travel motives. Future research should explore travel motives of domestic and international tourists separately, to compare the reasons for visit of these groups and derive the appropriate marketing strategies based on those findings. Moreover, the future study should include more respondents to surpass possible biases in making conclusions based on results.

\section{REFERENCES}

Božic, S., Spasojević, B., Vujičić, M., \& Stamenkovic, I. (2016). Exploring The Motives Of Religious Travel By Applying The Ahp Method: The Case Study Of Monastery Vujan (Serbia). International Journal of Religious Tourism and Pilgrimage, 4(4), Article 4. Retrieved September 16, 2016 from http://arrow.dit. ie/ijrtp/vol4/iss $4 / 4$

Crompton, J.L. (1979). Motivations for pleasure vacation. Annuals of Tourism Research, 6(4), 408-424.

Dann, G. (1981). Tourism motivation: an appraisal. Annals of Tourism Research, 8(2), 187-219. 
Erić, D. (2007). Strategija razvoja turizma grada Beograda. Beograd: Institut ekonomskih nauka.

Gaining Edge. (2016). Case study: Serbia Convention Bureau. Retrieved September 16, 2016 from http:// gainingedge.com/case-study-05/

ICCA. (2014). Statistics report 2014. Retrieved September 16, 2016 from www.iccaworld.com/dcps/doc. cfm?docid $=1789$

Hsu, C.H.C., \& Huang, S.S. (2008). Travel Motivation Theory and Research. In A.G. Woodside and D. Martin (Eds.), Tourism Management: Analysis, Behavior and Strategy. Cambridge, MA: CAB International

Jiang, S. (2015). Using means-end chain theory to explore travel motivation: An examination of Chinese outbound tourists. Journal of Vacation Marketing, 21(1), 87-100. doi:10.1177/1356766714535599

Maslow, A.H. (1943). A Theory of Human Motivation. Psychological Review, 50, 370-396.

Leong A.M.W., Yeh S.S., Hsia Y.C., \& Huan T.C.T.C. (2015). Nostalgia as travel motivation and its impact on tourists' loyalty. Journal of Business Research 68(1), 81-86. doi: 10.1016/j.jbusres.2014.05.003

Lee J., \& Lee H. (2015). Deriving Strategic Priority of Policies for Creative Tourism Industry in Korea using AHP. Procedia Computer Science. 3rd International Conference on Information Technology and Quantitative Management, ITQM 2015, (pp. 479-484).

Li, H., Pearce, P.L., \& Zhou, L. (2015). Documenting Chinese tourists' motivation patterns. In E. Wilson, $\mathrm{M}$. Witsel (Eds.), CAUTHE 2015: Rising Tides and Sea Changes: Adaptation and Innovation in Tourism and Hospitality, (pp. 235-246). Retrieved September 16, 2016 from http://search.informit.com.au/docu mentSummary;dn=210966631001071;res=IELBUS
Li, M., \& Cai, L.A. (2012). The effects of personal values on travel motivation and behavioral intention. Journal of Travel Research, 51(4), 473-487. doi:10.1177/0047287511418366

Pearce, P., Morrison, A.M., \& Rutledge, J.L. (1998). Tourism: Bridges Across Continents. Sydney: McGrawHill.

Pearce, P.L. (1995). Pleasure travel motivation. In R.W. McIntosh, C.R. Goeldner, \& J.R. Brent Ritchie (Eds.), Tourism: Principles, practices, philosophies, (pp. 167190). New York: John Wiley.

Plog, S.C. (1974). Why destination areas rise and fall in popularity. Cornell Hotel and Restaurant Quarterly, 14(4), 55-58.

Restorani Biz. (2016). Belgrade restaurants. Retrieved September 16, 2016 from http://www.restorani.biz/beograd/

Saaty, T. (1980). The Analytical Hierarchy Process: Planning, Priority Setting, Resource Allocation. New York: McGraw-Hill.

Saaty, T. (2008). Decision making with the analytic hierarchy process. International Journal of Services Sciences, 1(1), 83-98.

Sirakaya, E., \& Woodside, A.G. (2005). Building and testing theories of decision making by travellers. Tourism Management, 26(6), 815-832.

Vujović, B. (2003). Beograd. Beograd: IDEA.

Wang, X., Li, X., Zhen, F., \& Zhang, J.H. (2016). How smart is your tourist attraction? Measuring tourist preferences of smart tourism attractions via a FCEM-AHP and IPA approach. Tourism management, 54, 309320. doi:10.1016/j.tourman.2015.12.003 